J. Electroanal. Chem., 335 (1992) 163-186

Elsevier Sequoia S.A., Lausanne

JEC 02147

\title{
Oxygen reduction in acid media: effect of iron substitution by cobalt on heat-treated naphthalocyanine impregnations supported on preselected carbon blacks
}

\author{
A. Biloul, O. Contamin, G. Scarbeck and M. Savy * \\ LEI, CNRS, 1 place A. Briand, 92195 Meudon Cédex (France) \\ D. van den Ham \\ Twente University, 7500 AE Enschede (The Netherlands)
}

\section{J. Riga and J.J. Verbist}

Facultés Notre Dame de la Paix, B-5000 Namur (Belgium)

(Received 20 January 1992; in revised form 13 March 1992)

\begin{abstract}
FeNPc(1.2) impregnations were investigated at various loadings using a rotating-disk electrode, voltammetry and X-ray photoelectron spectroscopy (XPS) techniques. Optimal activity takes place at monolayer coverage, and major demetallation occurs after prolonged exposure to acid solution. The substitution of $\mathrm{Fe}$ by $\mathrm{Co}$ enables the electrochemical performances to reach those presented by $10 \% \mathrm{Pt}$ on Vulcan and stops the demetallation process. The application of fast atomic bombardment secondary ion mass spectrometry (FABS) together with XPS sheds light on the detrimental role of some electrophilic groups attached to the carbon black-catalyst interface.
\end{abstract}

\section{INTRODUCTION}

$\mathrm{Co}$ and $\mathrm{Fe}$ macrocyclic compounds are still a topic of interest as possible substitutes for Pt-based catalysts in air generator applications. Encouraging data at three-phase electrodes have recently been reported [1]. Performances comparable with those of Pt electrodes were found after pyrolysis of polypyrroles on carbon supports containing $\mathrm{Fe}$ and $\mathrm{Co}$ salts [2]. This activity was correlated with the formation of $\mathrm{MeN}_{4}$ units. Quantum chemical calculations have shown that, of the

* To whom correspondence should be addressed. 
various macrocyclic compounds, $\mathrm{Co}$ and $\mathrm{Fe}$ porphyrins appear to be the most suitable candidates for $\mathrm{O}_{2}$ reduction [3]. However, the effect of the support was not considered in this work. Improvement of the electrocatalytic properties of such materials on carbon supports appears to depend crucially on the effect of heat treatment [4].

In the case of phthalocyanines [5], dispersion seems to play an important rôle in the formation of ionized states with $\mathrm{O}_{2}$. The stacking of several layers of Co porphyrins turns out to be beneficial for $\mathrm{O}_{2}$ reduction in alkaline media [6]. In acid media relatively high activities were obtained on glassy carbon coated with films consisting of three to 80 layers of polymerized Co porphyrins [7]. Therefore the catalyst dispersion may present an optimal value which may be different for Co and $\mathrm{Fe}$ macrocycles.

Relatively few spectroscopic techniques can be used to provide an insight into the catalyst layer structure on carbon supports, particularly for the investigation of heat treatment effects. Extended X-ray absorption fine structure (EXAFS) measurements after heat treatment at various temperatures have shown that the optimal activity coincides with the conservation of the square planar structure of the metal [8,9]. However, as factors such as the dispersion of the catalyst and its interface with the carbon blacks seem to be very important in the determination of electrocatalytic performance, the X-ray photoelectron spectroscopy (XPS) technique may prove to be useful. The recent availability of fast atomic bombardment secondary ion mass spectrometry (FABS) equipment also provides new information on the nature of the species present at the catalyst-support interface.

The behavior of $\mathrm{FeNPc}(1.2)$, which is a mixture of four isomers, or $\mathrm{FeNPc}(2.3)$, which is a single isomer, deposited on various active charcoals such as Norit BRX or carbon blacks has been investigated before and after heat treatment by a number of workers [10-13]. The aim of the present paper is to compare different loadings of $\mathrm{FeNPc}(1.2)$ impregnation on the same active selected support (Printex $\mathrm{XE2}$ ) with equivalent loadings of $\mathrm{CoNPc}(1.2)$ in order to examine the rôle of the central ion on the activity for $\mathrm{O}_{2}$ reduction in an acid medium.

\section{EXPERIMENTAL}

\section{Preparation and characterization}

The preparation and characterization of various $\mathrm{FeNPc}(1.2)$ samples on Printex XE2 supports were achieved by similar procedures to those described in ref. 10 . They involve heating various amounts of DCN(1.2) powder mixed with Fe acetyl acetonate $\left(\mathrm{Fe}(\mathrm{AcAc})_{2}\right)$ in a mole ratio of $4 \mathrm{DCN}$ to $1 \mathrm{Fe}$ with carbon black powder in a sealed tube. The characterization is performed by dissolving the impregnated material in pyridine and comparing the spectra with those of the pure powder. The amounts of iron found by atomic absorption spectroscopy are given in Table 1 . The samples of supported and pure $\operatorname{CoNPc}(1.2)$ powder were prepared and characterized using the same procedure but with Co acetylacetonate $\operatorname{Co}\left(\mathrm{AcAc}_{2}\right)$. 
TABLE 1

Loading of FeNPc samples

\begin{tabular}{lll}
\hline Sample & $\mathrm{Fe} / \%$ & Loading/\% $/ \mathrm{w}$ \\
\hline 1 & $0.88-0.94$ & $12-12.9$ \\
2 & $2.05-2.26$ & $28-31$ \\
3 & $2.85-3.06$ & $39-42$ \\
\hline
\end{tabular}

Elemental analysis of naphthalocyanines shows that the reaction producing $\mathrm{CoNPc}(1.2)$ is more efficient than that producing $\mathrm{FeNPc}(1.2)$. The ratio $\mathrm{CoNPc}(1.2) /\left[\mathrm{H}_{2} \mathrm{NPc}(1.2)+\mathrm{CoNPc}(1.2)\right]$ is greater than $93 \%$ whereas it is about $60 \%$ in the case of FeNPc.

To our knowledge, no UV-Vis spectra of CoNPc(1.2) compounds (supported or unsupported) have been published prior to this investigation. The spectra obtained after exposure to $\mathrm{O}_{2}$ and prolonged $(4 \mathrm{~h})$ exposure to $\mathrm{N}_{2}$ are shown in Figs. 1(a) and 1(b) respectively. The same operating conditions (e.g. CoNPc(1.2) concentration in pyridine and cell path length) were used in both cases. The main differences between Figs. 1(a) and 1(b) occur in the Soret band with the emergence of additional peaks after exposure to $\mathrm{O}_{2}$. These transitions are characteristic of charge-transfer processes taking place between the metal ion $\left(\mathrm{Co}^{2+}\right)$ and the ligand in metalloporphyrins [14-16]. Therefore a ligand modification due to the attachment of an $\mathrm{O}_{2}$ molecule which would act as an electron acceptor from the metal ion center is suggested.

In order to check the compounds synthesized, FABS experiments were conducted. Mass spectra were obtained using a Finningan MAT 90 spectrometer equipped with a PDP 11/73 data system. The FABS measurements were carried out using an Ion Tech atomic gun unit, operating at $8 \mathrm{kV}$ and $1 \mathrm{~mA}$ (gun current). The target sizes correspond to standard equipment. Figure 2 (in the positive mode) reveals that the main component of the sample is CoNPc(1.2). The vacromium target was filled with the sample (approx. $2 \mathrm{mg}$ ) and $2 \mu \mathrm{l}$ of $\mathrm{n}$-nitrobenzylalcohol (NBA) as matrix and bombarded with a beam of xenon gas. The ions produced in this process were accelerated with a voltage of $5 \mathrm{kV}$ and analyzed by scanning the mass range from $m / z 50$ to $m / z 1200$ in $7 \mathrm{~s}$ with a resolution of 800 which is more than enough to characterize the molecules concerned here. Each compound was examincd in a positive or negative mode depending upon the sign of the acceleration voltage. Each measurement was the average of six scans.

The amount of cobalt in supported samples was determined by atomic absorption spectroscopy, and yielded a $\operatorname{CoNPc}(1.2)$ coverage loading of $25 \%-28 \% \mathrm{w} / \mathrm{w}$, comparable with sample 2 of FeNPc(1.2).

\section{Electrochemical equipment}

The electrochemical equipment is identical with that described elsewhere [1012]. The electrolyte consists of a solution of sulfuric acid $\left(0.25 \mathrm{M} \mathrm{H}_{2} \mathrm{SO}_{4}\right)$. The 

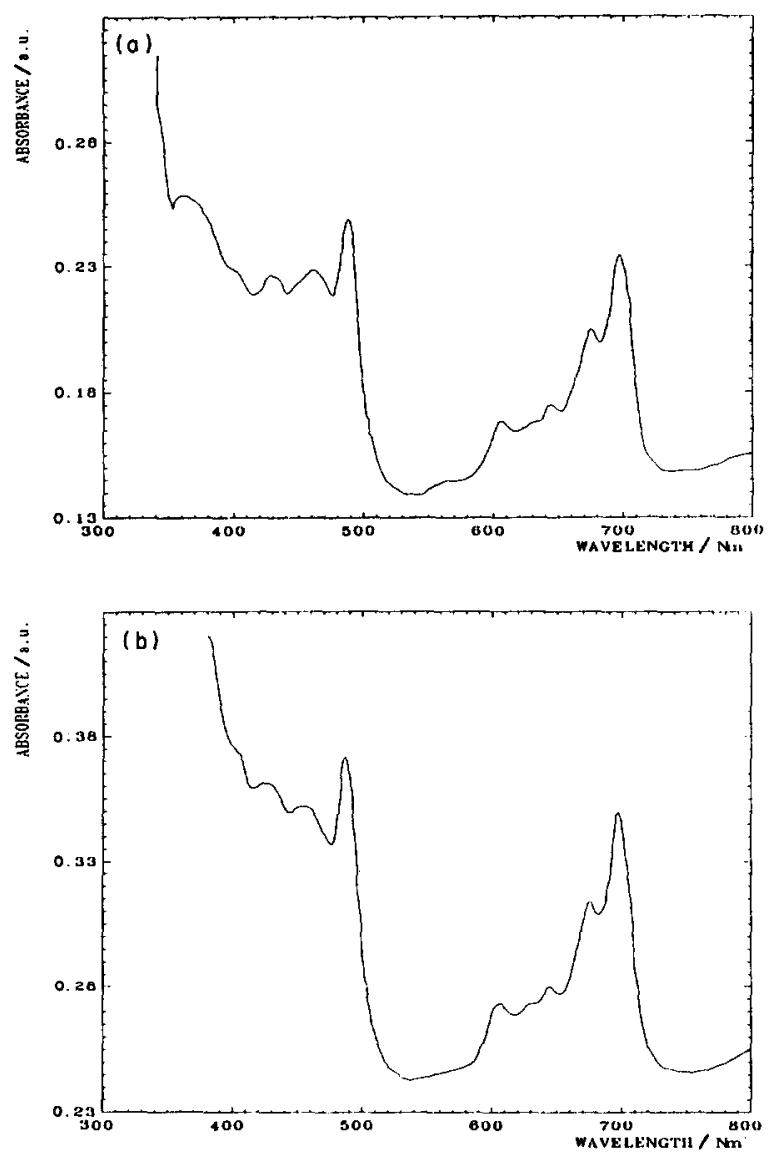

Fig. 1. UV-Vis spectra of CoNPc after exposure to (a) $\mathrm{O}_{2}$ and (b) $\mathrm{N}_{2}$.

surface area of the electrode is $0.125 \mathrm{~cm}^{2}$. The potentials are quoted with respect to the reversible hydrogen electrode (RHE).

\section{Electrode preparation}

The preparation of the rotating-disk electrode was also identical with that described in refs. 10-12. It consisted in fixing the carbon black impregnations in the disk cavity with a Teflon binding agent. The electrical contact was achieved by gold lacquer.

Sample 1 has been investigated earlier [13]. The present work is concerned with samples 2 and 3 from Table 1 and with CoNPc(1.2) impregnations at about the same loading as sample 2 . These impregnations were best for about 10 days in an 


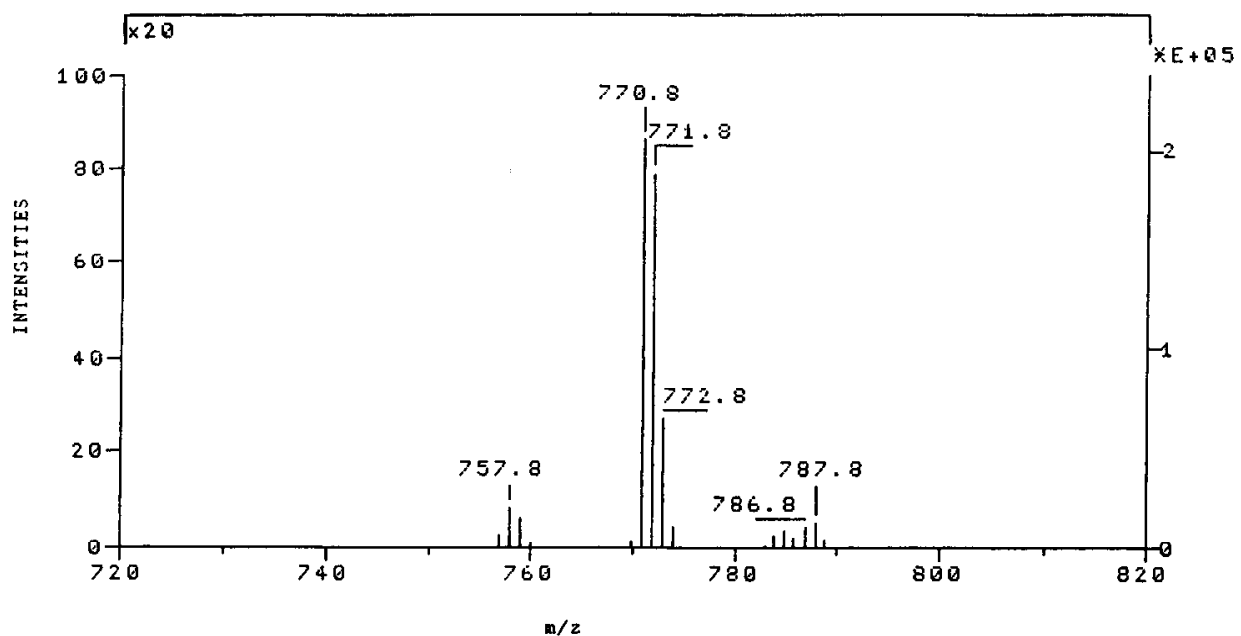

Fig. 2. FABS spectrum of pure $\operatorname{CoNPc}(1.2)$ powder (positive mode).

oxygenated sulfuric acid medium $(0.25 \mathrm{M})$ in order to stabilize. The samples were examined before and after heat treatment at $500^{\circ} \mathrm{C}$ for $2 \mathrm{~h}$ under nitrogen.

\section{XPS experiments}

In order to obtain an insight into the influence of the substrate on the electrocatalytic behavior of the samples, XPS investigations using an HP 5050 monochromatized spectrometer were performed [10-12] on samples which had been stored for 10 days in $0.25 \mathrm{M} \mathrm{H}_{2} \mathrm{SO}_{4}$ solution under oxygen.

\section{RESULTS AND DISCUSSION}

\section{Effect of the loading on $\mathrm{FeNPc}(1.2)$ impregnations}

Figures 3(a) and 3(b) show $I-E$ curves for $\mathrm{O}_{2}$ reduction at various rotation frequencies $f$ on non-heat-treated $\mathrm{FeNPc}(1.2)$ impregnations at $30 \%$ and $40 \%$ loadings respectively. These curves are corrected from the current under nitrogen and identical activities can be seen. The data can be compiled using a KouteckyLevich plot [17] $\left(1 / I\right.$ vs. $\left.f^{-1 / 2}\right)$. The total number $N$ of exchanged electrons is found from the slope to be 3.5. In addition, it has been shown [18] that curves of this shape are characteristic of a reaction mechanism involving a limiting adsorption step.

The voltammograms at various scanning velocities under $\mathrm{O}_{2}$ and $\mathrm{N}_{2}$ are presented in Figs. 4(a) and 4(b) for FeNPc(1.2) impregnations at 30\% loadings. Under $\mathrm{O}_{2}$ a hump identical with those reported previously [10-13] can be observed. On the basis of the voltammograms, a redox mechanism cannot be 

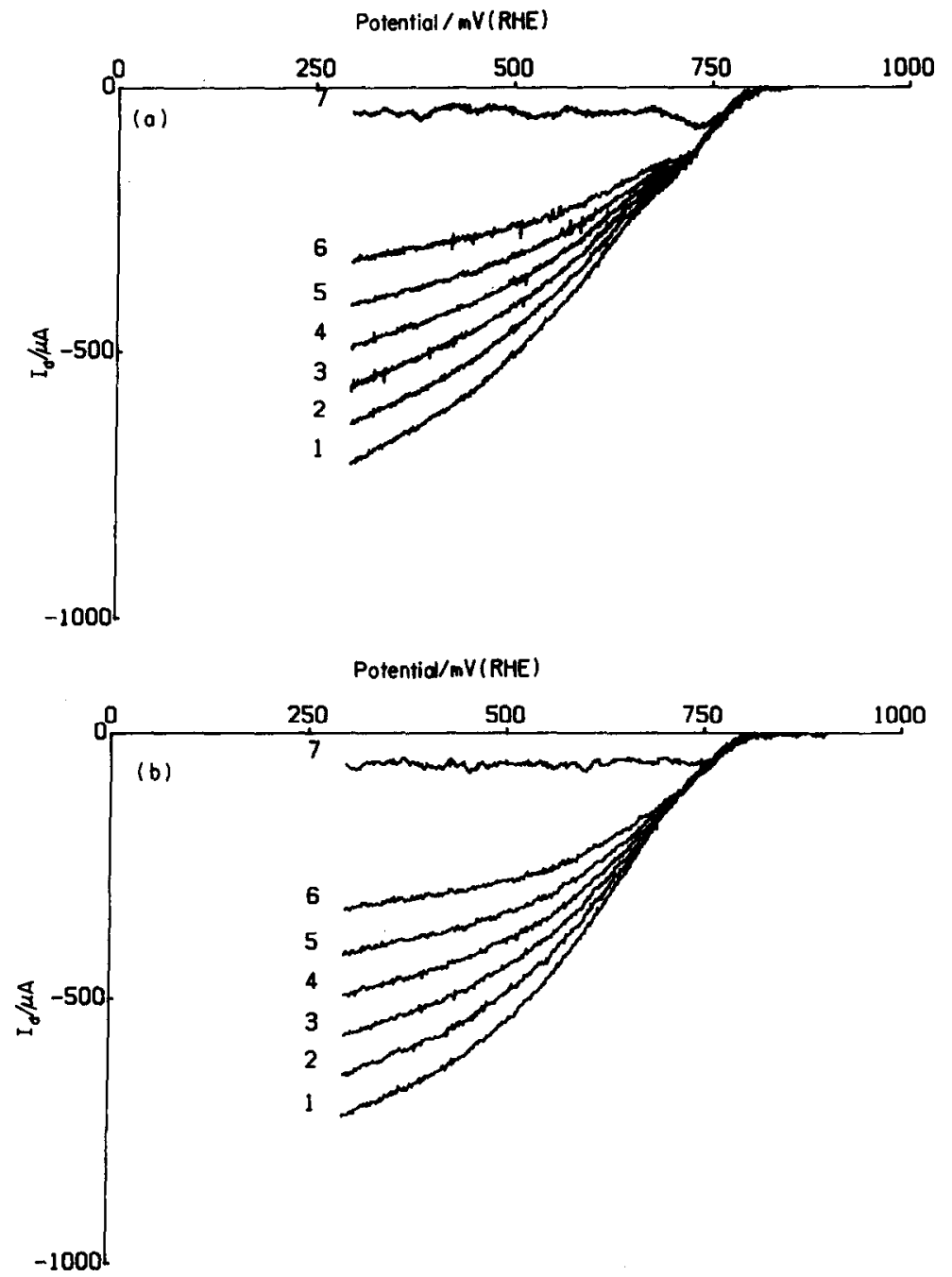

Fig. 3. $I-E$ curves (corrected from the current under $\mathrm{N}_{2}$ ) at various rotation frequencies for $\mathrm{O}_{2}$ reduction on non-heat-treated FeNPc(1.2) loaded at (a) $30 \%$ and (b) $40 \%$ (scanning velocity, $1.5 \mathrm{mV}$ $\mathrm{s}^{-1}$ ): (1) $64 \mathrm{rev} \mathrm{s}^{-1}$; (2) $49 \mathrm{rev} \mathrm{s}^{-1}$; (3) $36 \mathrm{rev} \mathrm{s}^{-1}$; (4) $25 \mathrm{rev} \mathrm{s}^{-1}$; (5) $16 \mathrm{rev} \mathrm{s}^{-1}$; (6) $9 \mathrm{rev} \mathrm{s}^{-1}$; (7) $0 \mathrm{rev}$ $s^{-1}$.

invoked because the position of the cathodic peak is negative with respect to the beginning of $\mathrm{O}_{2}$ reduction. For $40 \%$ loadings the voltammograms under $\mathrm{O}_{2}$ and $\mathrm{N}_{2}$ present a similar shape but with a charge density roughly half the size which can be attributed to an effect of the double-layer capacity.

Figure 5 shows, as a reference, $I-E$ curves for the same rotation frequencies as those used above obtained on FeNPc(1.2) loaded at $10 \%$ corrected from the curve 

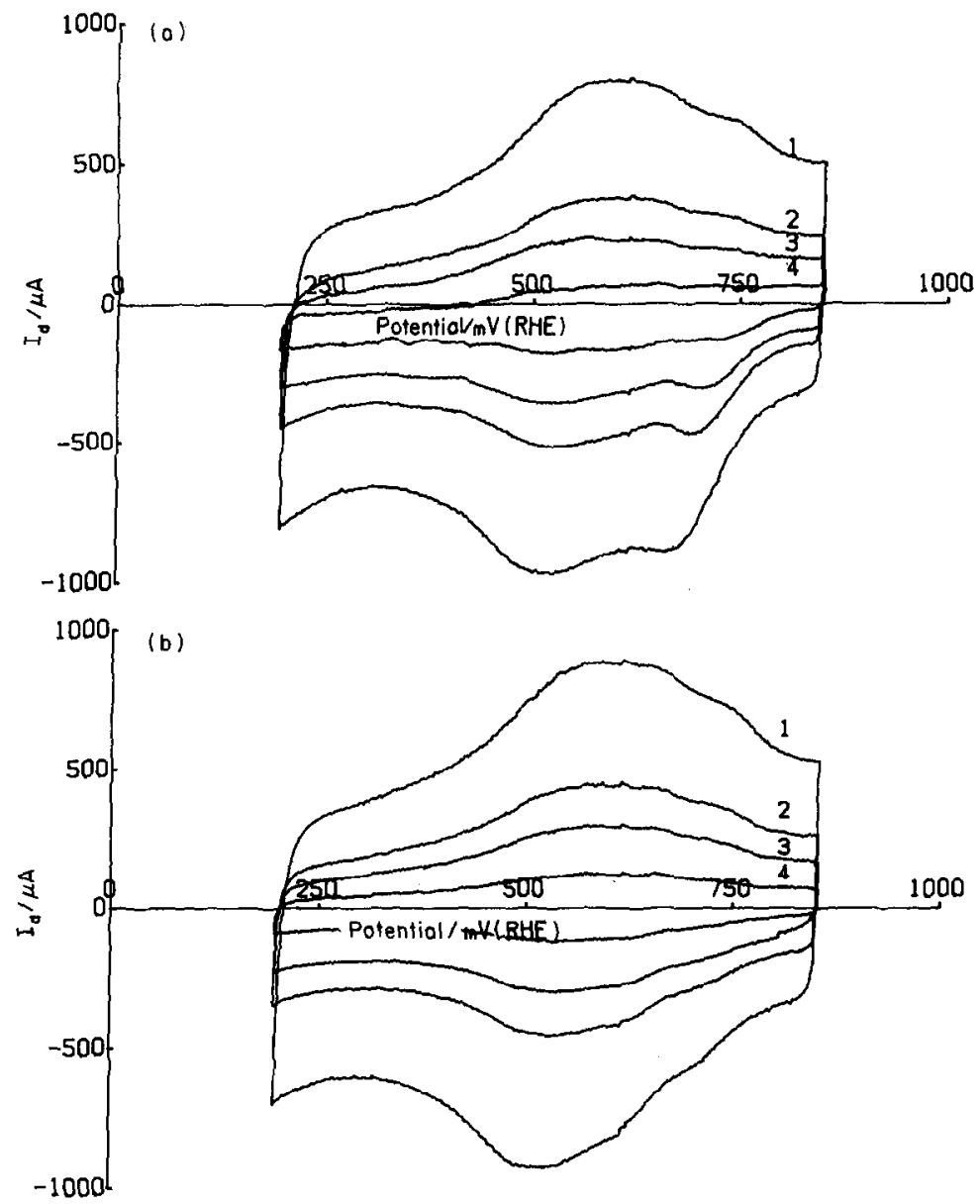

Fig. 4. Voltammograms obtained at a stationary electrode on non-treated FeNPc(1.2) with $30 \%$ loading at various scanning velocities under (a) $\mathrm{O}_{2}$ and (b) $\mathrm{N}_{2}$ : (1) $10.8 \mathrm{mV} \mathrm{s}^{-1}$; (2) $5.4 \mathrm{mV} \mathrm{s}^{-1}$; (3) $3.6 \mathrm{mV} \mathrm{s}^{-1}$; (4) $1.5 \mathrm{mV} \mathrm{s}^{-1}$. The scans were recorded after electrode stabilization.

under $\mathrm{N}_{2}$. These samples were investigated previously [13]. It should be noted that there is a limiting current which obeys the Levich plot $I_{\mathrm{L}}$ vs. $f^{1 / 2}$ and the relationship

$E \propto \log \left[I /\left(I_{\mathrm{L}}-I\right)\right]$

with a slope of $105 \mathrm{mV}$ per decade characteristic of a diffusion-limiting step coupled with a one-electron transfer.

Therefore the electrochemical activity on non-heat treated samples of FeNPc(1.2) reached a maximum at a loading of about $10 \%$. For higher values the kinetics are modified mainly through a deceleration of the $\mathrm{O}_{2}$ adsorption step. At a loading of $30 \%$ the activity is stabilized. 


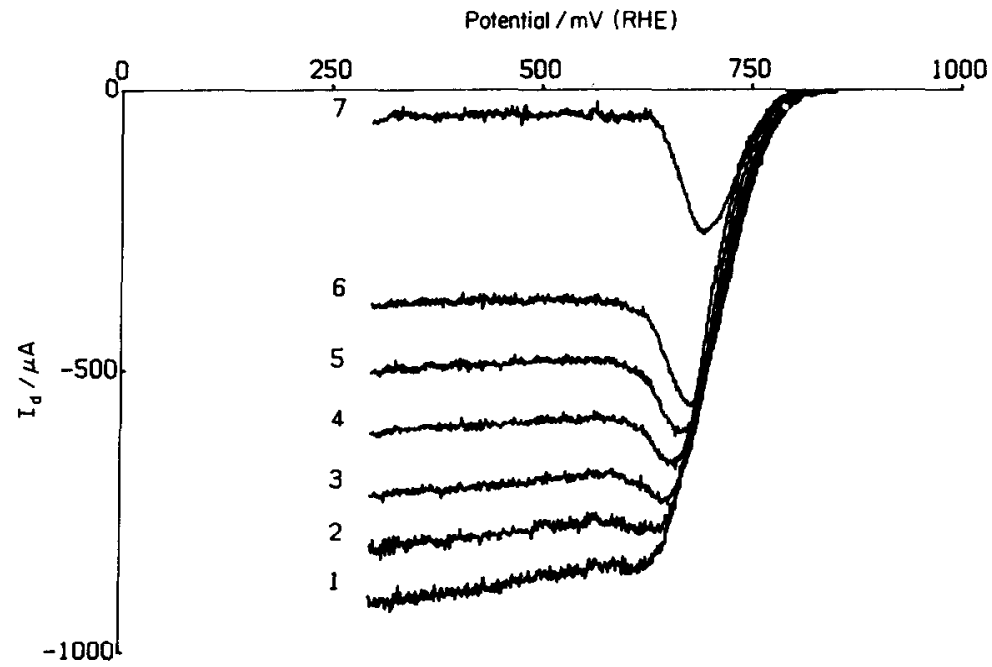

Fig. 5. $I-E$ curves at various rotation frequencies for $\mathrm{O}_{2}$ reduction on non-heat-treated $\mathrm{FeNPc}(1.2)$ with $10 \%$ loading. Same conditions as Fig. 3.

The effect of heat treatment on different FeNPc(1.2) loadings is shown in Fig. 6 for the same rotation frequency of $64 \mathrm{rev} \mathrm{s}^{-1}$. The samples loaded at $10 \%$ remain the most active, whereas those loaded at $40 \%$ are unaffected. In the region of transfer limitation, the current at $30 \%$ loading is about half that at $10 \%$ loading.

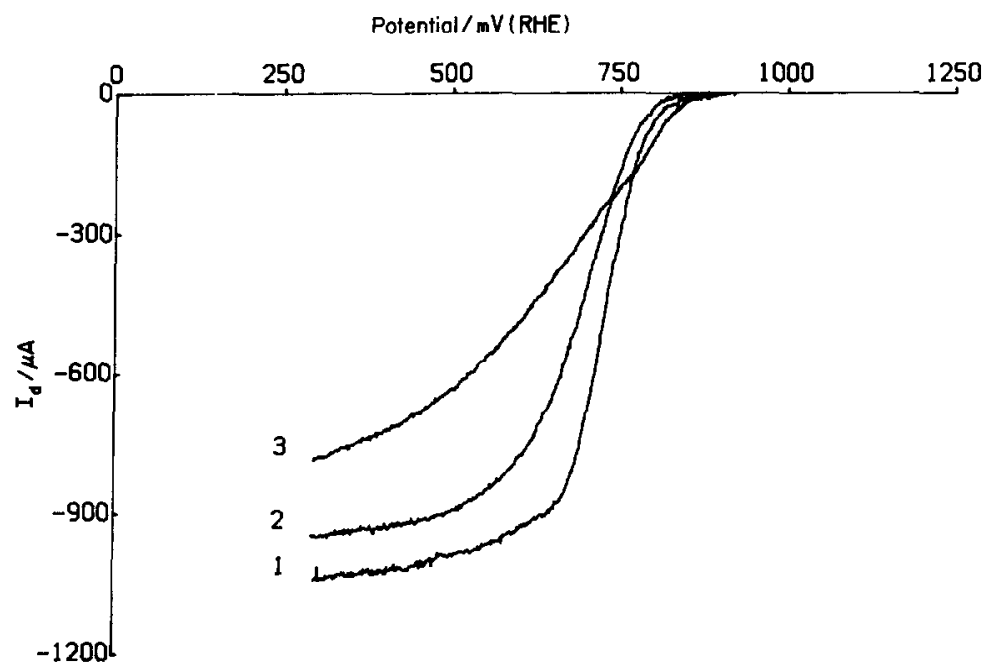

Fig. 6. $I-E$ curves obtained at $64 \mathrm{rev} \mathrm{s}^{-1}$ for $\mathrm{O}_{2}$ reduction on heat-treated FeNPc(1.2) impregnations at different loadings. (1) $10 \%$; (2) $30 \%$; (3) $40 \%$. Scanning velocity $1.5 \mathrm{mV} \mathrm{s}^{-1}$. 


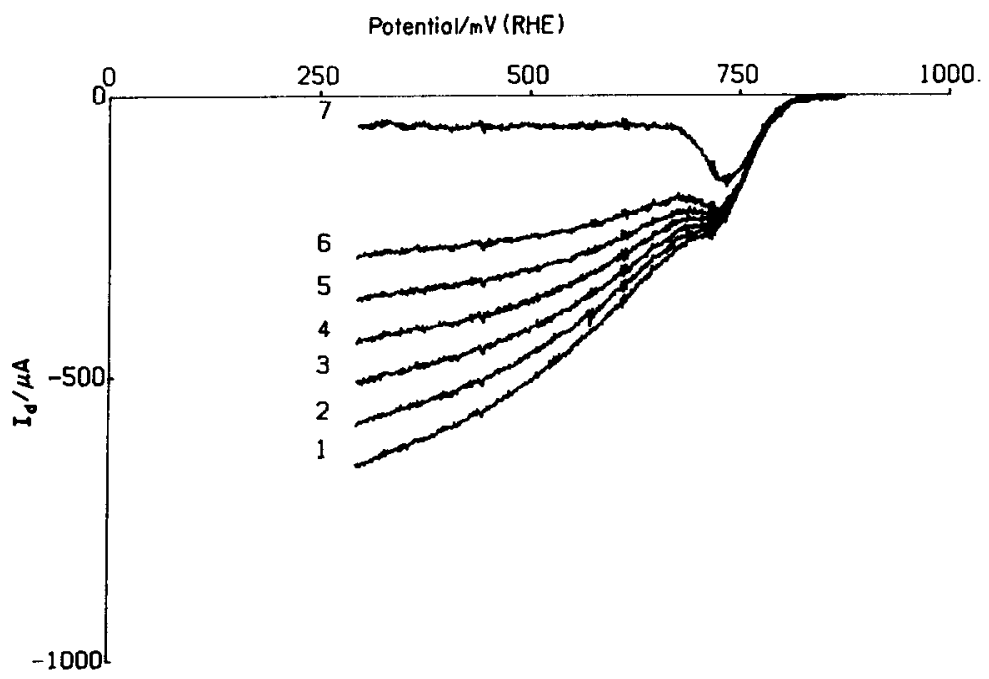

Fig. 7. $I-E$ curves obtained under the same conditions as Fig. 3 for $\mathrm{O}_{2}$ reduction on non-heat-treated CoNPc(1.2) samples at 27\% loading. Rotation frequencies as in Figs. 3(a) and 3(b).

This result can be interpreted in terms of either a partially blocked electrode [19] or a diminution of the transfer kinetic constant.

$\operatorname{CoNPc}(1.2)$ samples (27\% loading)

Figure 7 shows $I-E$ curves for $\mathrm{O}_{2}$ reduction on non-heat-treated $\operatorname{CoNPc}(1.2)$ samples at $27 \%$ loading obtained under the same conditions as Fig. 3. The major difference is the improved activities at potentials more positive than about 650 $\mathrm{mV} /$ RHE. Otherwise these curves are similar to those obtained on $\operatorname{FeNPc}(1.2)$ at $30 \%$ or $40 \%$ loadings, and the same conclusions can be drawn concerning the kinetic processes involved.

The voltammograms obtained for non-heat-treated $\mathrm{CoNPc}(1.2)$ samples under $\mathrm{O}_{2}$ and $\mathrm{N}_{2}$ are shown in Figs. 8(a) and 8(b) respectively. Whereas no peak is visible in Fig. 8(b), the $\mathrm{O}_{2}$ adduct with higher intensity, which is also present in the UV-Vis spectra (Fig. 1), can be seen in Fig. 8(a) and can explain the improved activities found in this potential domain compared with the $\mathrm{Fe}$ samples. The comparison of these voltammograms with $I-E$ curves supports the conclusion drawn above that there is no redox process in the reaction path.

$I-E$ curves for $\mathrm{O}_{2}$ reduction on heat-treated $\mathrm{CoNPc}(1.2)$ samples at $27 \%$ loading are shown in Fig. 9(a) for the same conditions as Fig. 3(a). The most salient feature is the existence of a limiting current $I_{\mathrm{L}}$ obeying the Levich relationship $I_{\mathrm{L}} \propto f^{1 / 2} . E$ vs. $\log I /\left(I_{\mathrm{L}}-I\right)$ plots are obtained with a slope of 65 $\mathrm{mV}$ per decade. 

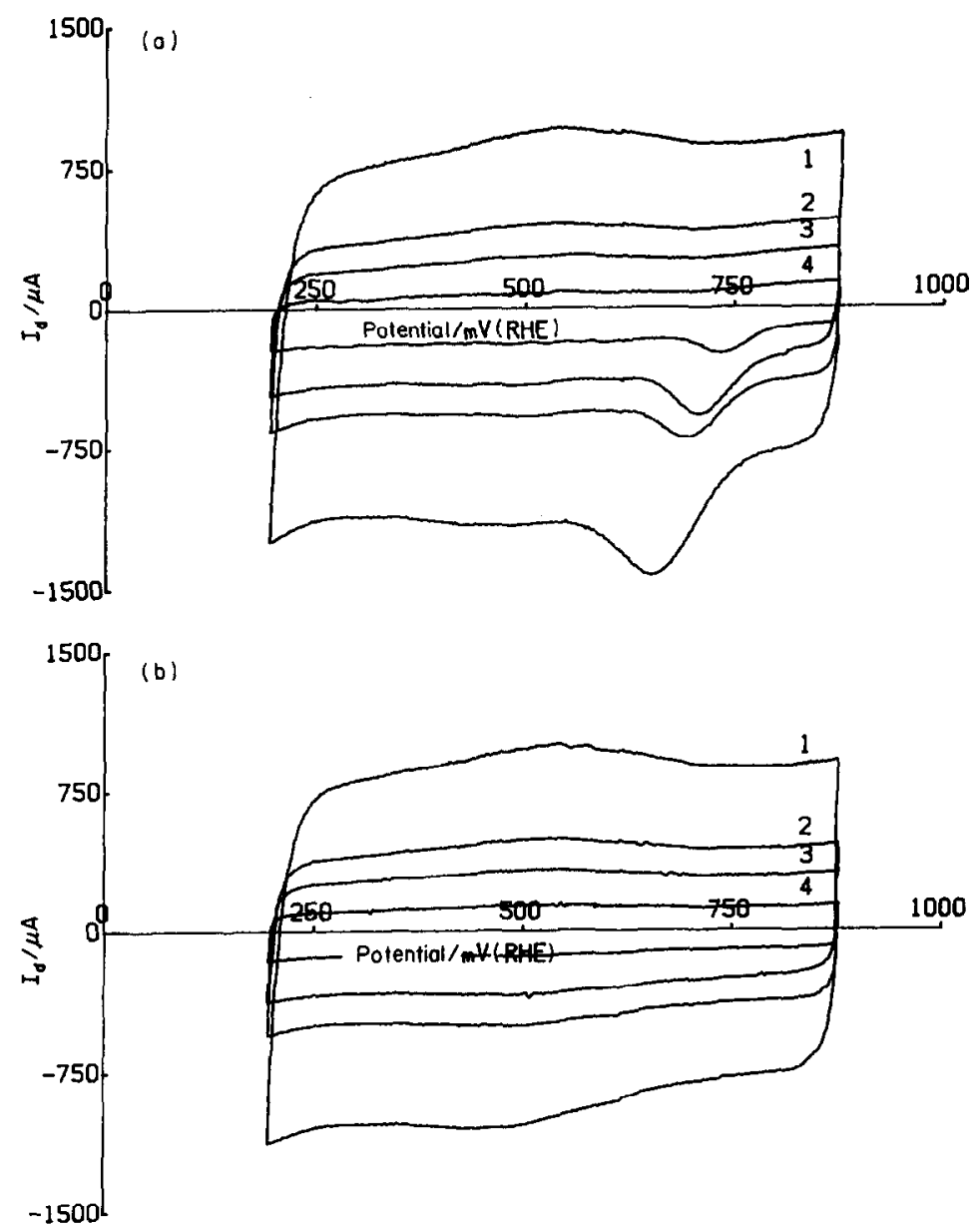

Fig. 8. Voltammograms obtained under the same conditions as Fig. 4 for non-heat-treated $\mathrm{CoNPc}(1.2)$ samples at $27 \%$ loading under (a) $\mathrm{O}_{2}$ and (b) $\mathrm{N}_{2}$.

It is instructive to compare the data obtained at $64 \mathrm{rev} \mathrm{s}^{-1}$ with those obtained under the same conditions for $10 \% \mathrm{w} / \mathrm{w}$ Pt on Vulcan (Fig. 9(b)). They also exhibit a limiting current with a potential $E_{1 / 2}\left(E\right.$ at $\left.I_{\mathrm{L}} / 2\right)$ identical with that for the CoNPc(1.2) samples loaded at $27 \%$. It should be noted that in the potential domain 700-800 $\mathrm{mV} / \mathrm{RHE}$ the activities are almost the same for both samples. In the same potential range $\mathrm{CoNPc}(1.2)$ samples loaded at $27 \%$ display higher charge densities than FeNPc(1.2) samples loaded at $10 \%$ and above.

Voltammograms obtained on heat-treated CoNPc samples loaded at $27 \%$ are presented in Figs. 10(a) and 10(b) for $\mathrm{O}_{2}$ and $\mathrm{N}_{2}$ respectively under the same conditions as in Figs. 4(a) and 4(b). Compared with the voltammogram under $\mathrm{O}_{2}$ (Fig. 8(a)) the intensity of the peak due to the oxygen adduct in Fig. 10(a) should 

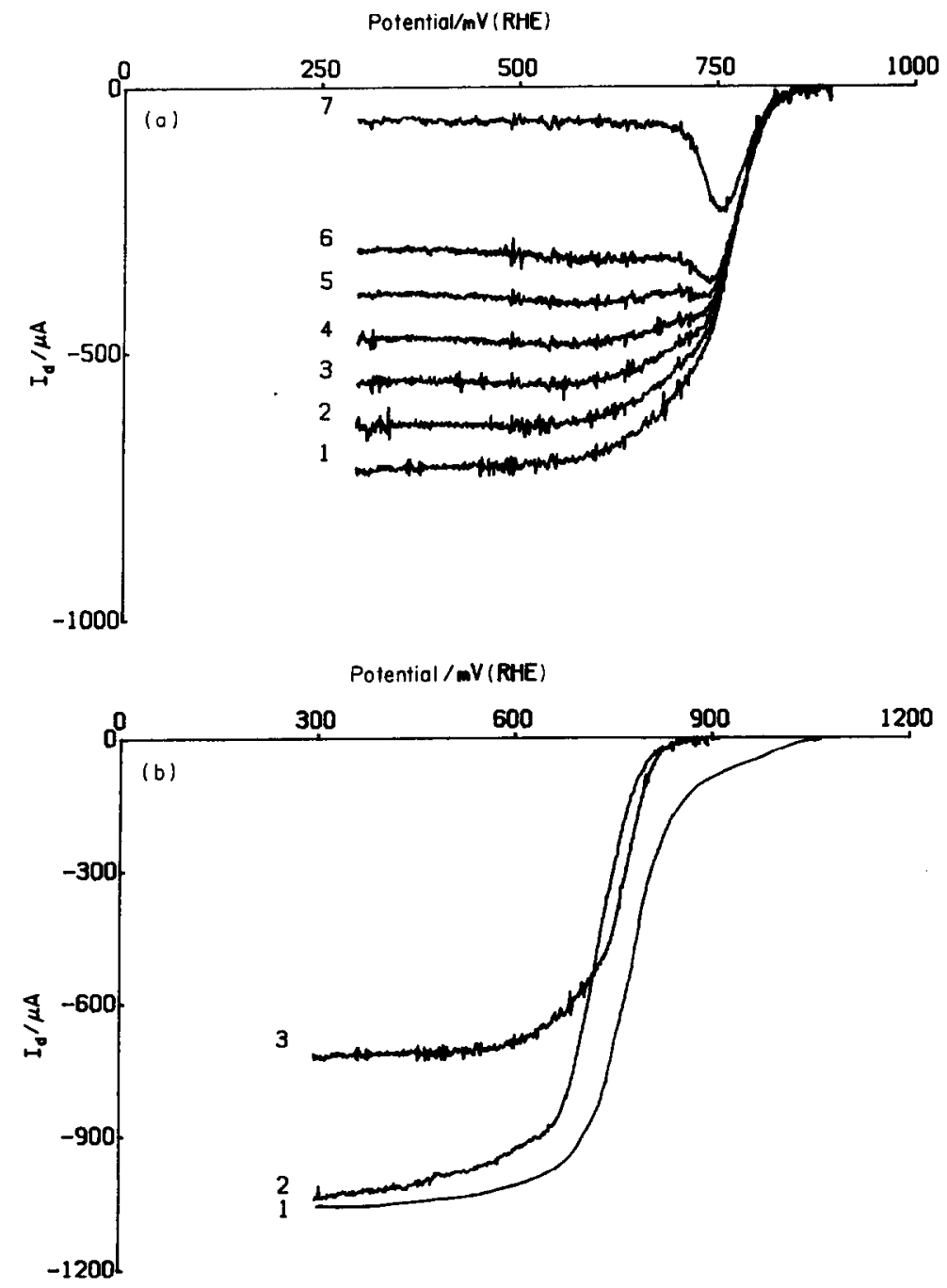

Fig. 9. (a) $I-E$ curves for $\mathrm{O}_{2}$ reduction of heat-treated CoNPc(1.2) samples at 27\% loading under the same conditions as in Fig. 3. (b) Comparison of these samples with $10 \% \mathrm{w} / \mathrm{w}$ Pt on Vulcan under the same conditions (rotation frequency, $64 \mathrm{rev} / \mathrm{s}$ ): (1) $10 \% \mathrm{w} / \mathrm{w} \mathrm{Pt}$ on Vulcan; (2) heat-treated $10 \% \mathrm{w} / \mathrm{w}$ FeNPc on Printex XE2; (3) heat-treated 27\% w/w CoNPc(1.2) on Printex XE2.

be noted. It suggests an increased $\mathrm{O}_{2}$ uptake due to the heat treatment. The voltammograms under $\mathrm{N}_{2}$ are remarkably flat, thus ruling out any possibility of a redox process in the $\mathrm{O}_{2}$ reduction pathway.

\section{XPS measurements}

The effect of heat treatment on FeNPc(1.2) samples loaded at $10 \%$ has heen examined using XPS techniques in previous work [13]. The average number $n$ of 

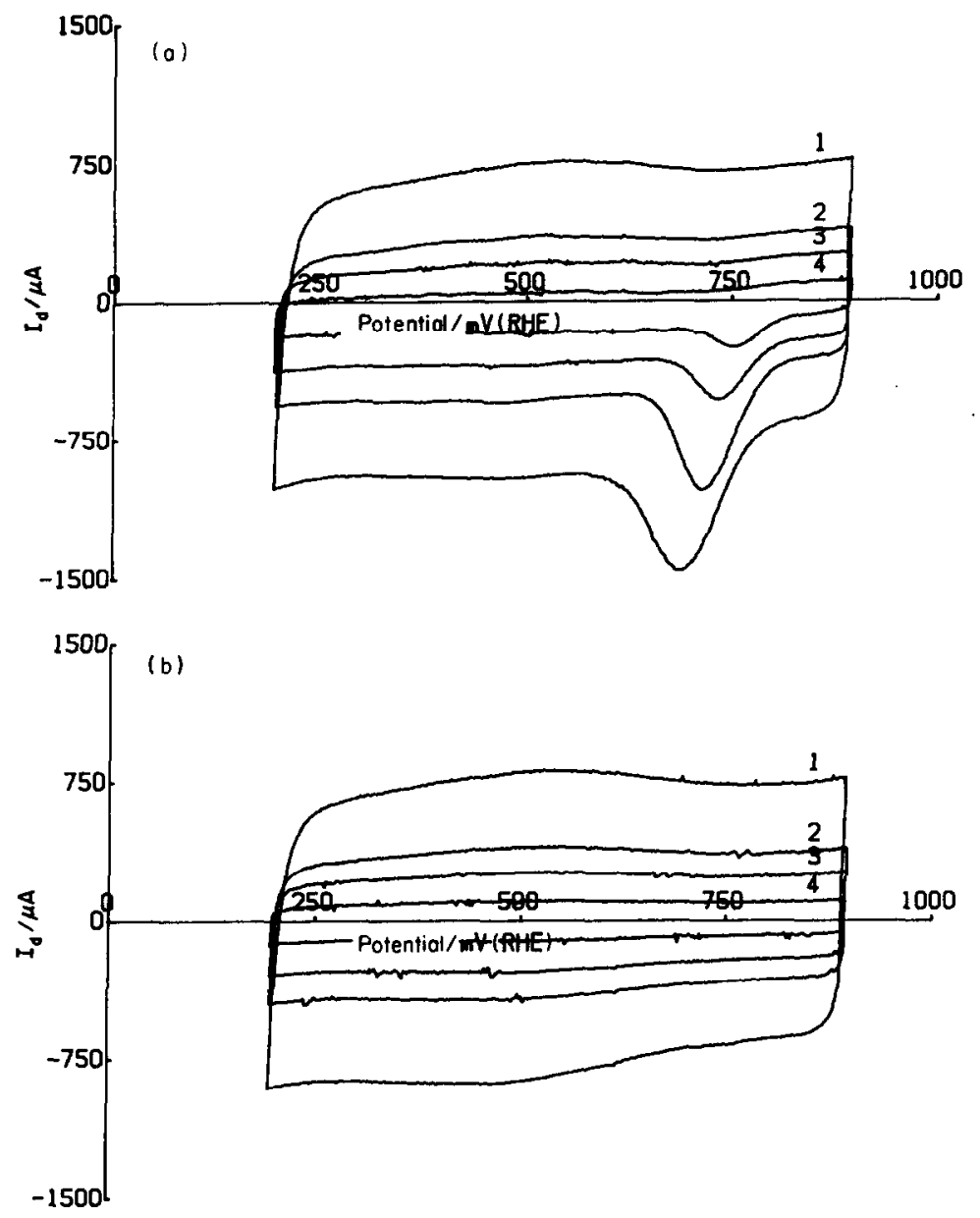

Fig. 10. Voltammograms obtained under the same conditions as Fig. 4 on heat-treated $\mathrm{CoNPc}(1.2)$ samples at $27 \%$ loading under (a) $\mathrm{O}_{2}$ and (b) $\mathrm{N}_{2}$.

catalyst layers on the support can be calculated from [20]

$$
\frac{I_{\mathrm{e}}}{I_{\mathrm{e}_{\infty}}}=\frac{r L}{100 A_{\mathrm{s}} d} \frac{1-\exp (-n s / \lambda)}{n s}
$$

where $A_{\mathrm{s}} / \mathrm{cm}^{2} \mathrm{~g}^{-1}$ is the specific surface area of the support, $d \approx 2 \mathrm{~g} \mathrm{~cm}^{-3}$ is the density of the element, $r \approx 4$ is the roughness factor [20], $\lambda=20-25 \AA$ is the electron mean free path in the carbon substrate [9], $s=3.5 \AA$ is the thickness of a layer, $L$ is the loading (in wt.\% of the element), $I_{\mathrm{e}}$ is the intensity from a very thin layer and $I_{e_{\infty}}$ is the intensity from the bulk material.

Equation (1) holds only if the thickness of the crystallites is less than the electron mean free path in the catalyst layers, e.g. $20 \AA$ which is equivalent to four 


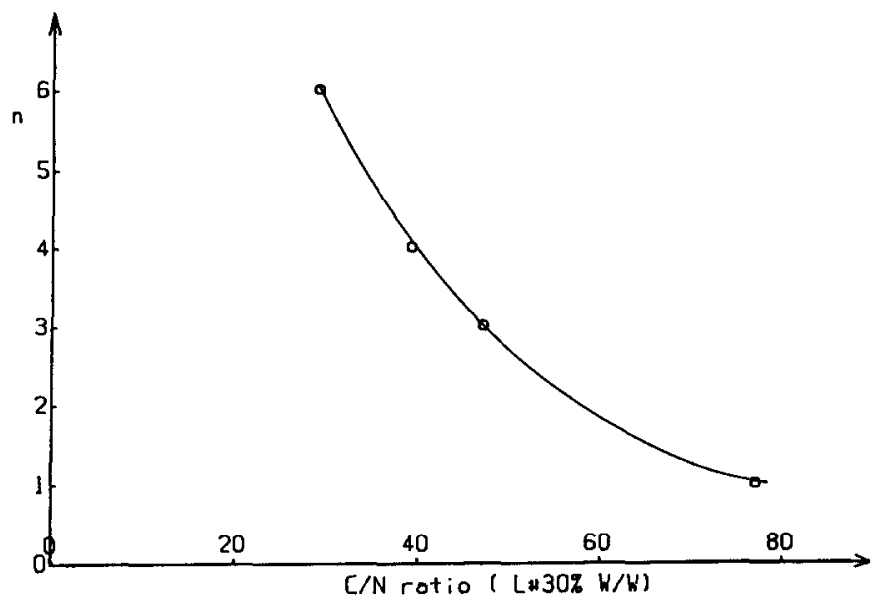

Fig. 11. Representation of $n$ (catalyst layer number) as a function of the $C / N$ ratio (from eqn. (1)).

or five layers. According to eqn. (1), larger crystallites would yield an average $n$ below its real value. At a constant loading value an increase of $n$ resulting from the application of eqn. (1) implies a redistribution of the crystallites on the surface.

The different atomic ratios for the various $\mathrm{FeNPc}(1.2)$ impregnations are determined according to the methods of Elliot et al. [22]. From eqn. (1) it is possible to express $n$ as a function of the $\mathrm{C} / \mathrm{N}$ ratio (Fig. 11).

FeNPc(1.2) samples

The different atomic ratios for $\mathrm{FeNPc}(1.2)$ samples at various loadings after storage for 10 days in $\mathrm{H}_{2} \mathrm{SO}_{4}$ solution are given in Table 2. From this table, it can be seen that the optimum activity is reached for monolayer coverage, which is realized for $10 \%$ loading after heat treatment. According to the electrochemical data, for $n>1$ the $\mathrm{O}_{2}$ active adsorption step is impeded and the electrode activities are independent of the catalyst thickness. It should be noted that despite

TABLE 2

Atomic ratios for various FeNPc loadings

\begin{tabular}{lcccc}
\hline & Non-treated & \multicolumn{2}{l}{ Heat-treated } & \\
\cline { 3 - 5 } & $10 \%$ & $10 \%$ & $30 \%$ & $40 \%$ \\
\hline $\mathrm{C} / \mathrm{Fe}$ & 2000 & 2600 & 1215 & 773 \\
$\mathrm{C} / \mathrm{N}$ & 62 & 77 & 39 & 29 \\
$\mathrm{C} / \mathrm{O}$ & 46 & 34 & 37 & 29 \\
$\mathrm{~N} / \mathrm{Fe}$ & 32 & 34 & 31 & 27 \\
$\mathrm{O} / \mathrm{N}$ & 1.35 & 2.26 & 1.05 & 1 \\
$n$ & 2 & 1 & 4 & 6 \\
\hline
\end{tabular}




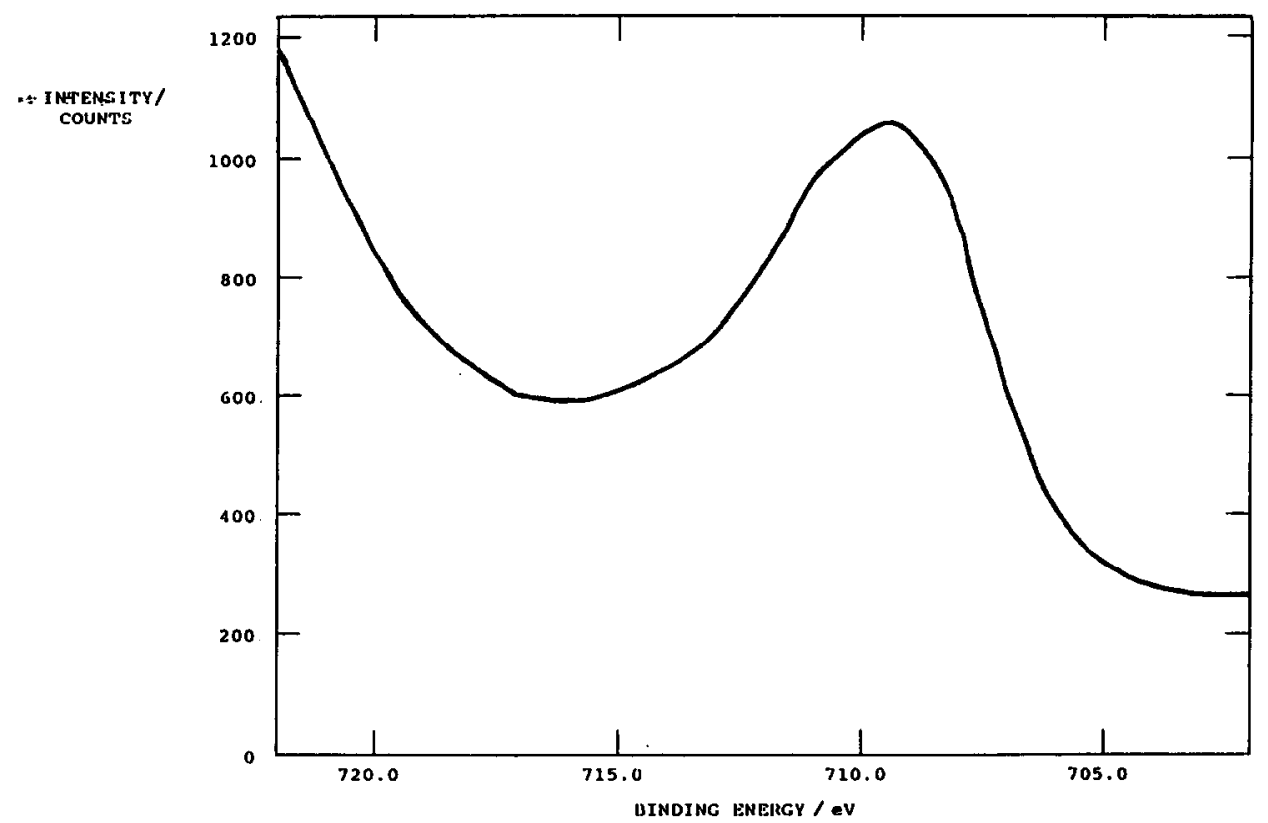

Fig. 12. Fe 2p spectrum (counts versus binding energies) of FeNPc(1.2) samples loaded at $30 \%$ or $40 \%$.

the increase in $n$ the $\mathrm{N} / \mathrm{Fe}$ ratio characteristic of demetallation does not vary significantly. This fact supports the view of proton penetration in the catalyst layers enabling the demetallation process to take place.

The $\mathrm{Fe} 2 \mathrm{p}$ spectra of the samples loaded at $30 \%$ and $40 \%$ are similar to those shown in Fig. 12. A mixture of Fe(II) and Fe(III) is obtained.

The $\mathrm{C} / \mathrm{O}$ ratios given in Table 2 clearly show an oxygen uptake due to the heat treatment. As $n$ increases, some oxygen appears to be inserted into the catalyst layers, but this process has little influence on the activity. The $\mathrm{O} 1 \mathrm{~s}$ spectra are similar to those of bound oxygen reported in ref. 13 . The $\mathrm{N} 1 \mathrm{~s}$ spectra are also very similar to those shown for heat-treated samples loaded at $10 \%$. The ratios $I_{400.1} / I_{398.5}$ of the intensity peaks, which are 0.52 and 0.45 respectively for samples loaded at $30 \%$ and $40 \%$ (Fig. 13), lie close to those reported [4] for the most active samples.

Therefore in the case of $\operatorname{FeNPc}(1.2)$ impregnations, the main correlation of the XPS data with the electrochemical activities concerns the value of $n$. The optimal activity occurs at monolayer coverage, shedding some light on a special configuration composed of the $\mathrm{FeN}_{4}$ unit fixed at the carbon black surface.

\section{$\operatorname{CoNPc}(1.2)$ samples}

Table 3 shows the atomic ratios for both untreated and heat-treated CoNPc(1.2) samples before and after storage for 10 days in $0.25 \mathrm{M} \mathrm{H}_{2} \mathrm{SO}_{4}$ solution. The data were determined using the method of Elliot et al. [22]. The major difference from 
177
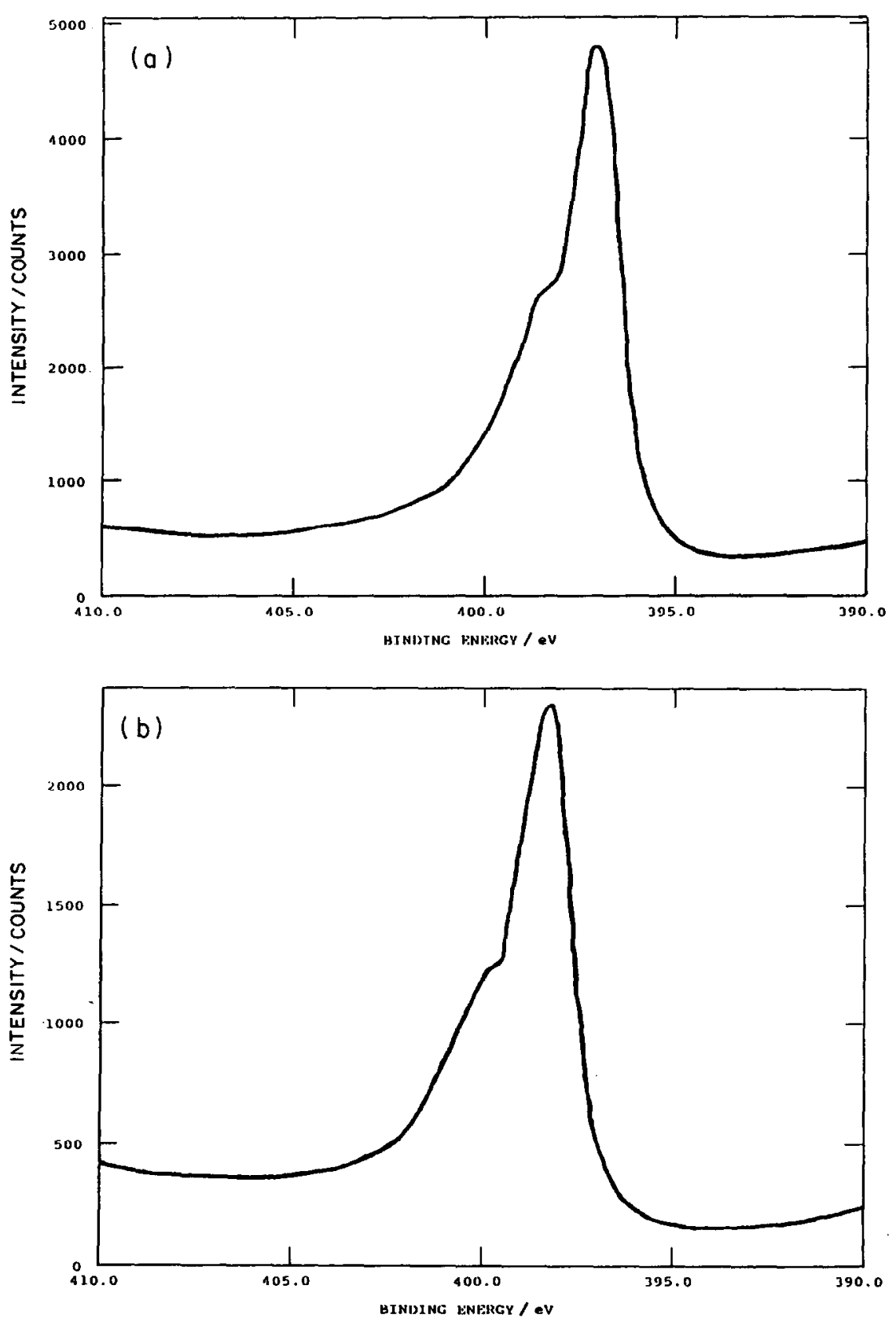

Fig. 13. N 1s spectra of heat-treated FeNPc(1.2) samples loaded at (a) $30 \%$ and (b) $40 \%$. 
TABLE 3

Atomic ratios for CoNPc(1.2) samples loaded at $27 \%$ on Printex XE2

\begin{tabular}{lcccc}
\hline & $\begin{array}{l}\text { Non-heat- } \\
\text { treated }\end{array}$ & $\begin{array}{l}\text { Heat- } \\
\text { treated }\end{array}$ & $\begin{array}{l}\text { Non-heat-treated } \\
+\mathrm{H}_{2} \mathrm{SO}_{4} \text { solution }\end{array}$ & $\begin{array}{l}\text { Heat treated } \\
+\mathrm{H}_{2} \mathrm{SO}_{4} \text { solution }\end{array}$ \\
\hline $\mathrm{C} / \mathrm{N}$ & 67 & 55 & 40 & 47 \\
$\mathrm{C} / \mathrm{O}$ & 48 & 52 & 20 & 28 \\
$\mathrm{~N} / \mathrm{Co}$ & 18 & 16 & 14 & 18 \\
$\mathrm{C} / \mathrm{Co}$ & 1200 & 885 & 552 & 840 \\
$\mathrm{O} / \mathrm{Co}$ & 25 & 17 & 28 & 30 \\
$\mathrm{O} / \mathrm{N}$ & 1.4 & 1.1 & 2 & 1.7 \\
$n$ & $\neq 1.5$ & 2 & 4 & 3 \\
\hline
\end{tabular}

the data for iron samples reported in ref. 13 and Table 2 is found in the N/Co ratio which remains constant regardless of heat or solution treatment. In contrast with the iron samples, no demetallation by the acid solution can be detected. An increase in $n$ and in oxygen uptake after storage in the acid solution can be seen. According to consideration of eqn. (1), as discussed above, an increase in $n$ at constant loading implies a redistribution of catalyst crystallites on the support. At the same loading $(27 \%-30 \%)$ the $\mathrm{O} / \mathrm{N}$ ratio in CoNPc is twice that in FeNPc whereas the $n$ values are comparable.

The $O$ 1s spectra of both heat-treated and untreated CoNPc(1.2) samples stored for 10 days in acid solution are similar (Fig. 14). Their shape and position of the maximum are identical with those presented by iron samples and are characteristic of bound oxygen with the maximum at $531.5 \mathrm{eV}$.

In the case of Co $2 p$ spectra (Fig. 15) the action of the acid solution induces only minor changes for heat-treated samples and no visible modification for untreated samples. Deconvolution of the peak yields about the same amount of $\mathrm{Co}$ (II) and $\mathrm{Co}$ (III) after storage in acid, and $40 \% \mathrm{Co}$ (II) and $60 \% \mathrm{Co}$ (III) for heat-treated samples before exposure to the acid solution.

Figure 16 shows the N 1s spectra for heat-treated and non-heat-treated CoNPc samples before and after storage in acid solution. The most salient feature concerns the effect of the acid solution. On non-heat-treated samples oxidation of the nitrogen atoms is apparent, with the peak maximum shifting from 398.5 to $399.5 \mathrm{eV}$ and the shoulder intensity ratio $I_{400.5} / I_{\max }$ increasing from 0.3 to 0.55 . The results presented in Table 3 show that prolonged storage in acid solution results in an increase in the number of catalyst layers and the amount of inserted oxygen. The shift in the position of the $\mathrm{N} 1 \mathrm{~s}$ maximum suggests that heat treatment impedes the oxidation of the nitrogen atoms.

It should be noted that the $I_{400.5} / I_{398.5}$ ratio for active CoNPc is much lower than that for both active (10\% loading) [13] and less active (30\% loading) FeNPc samples, which is characteristic of lower oxidation despite a higher oxygen content. This unusual behavior emphasizes the possible electron-donor rôle of the surface 


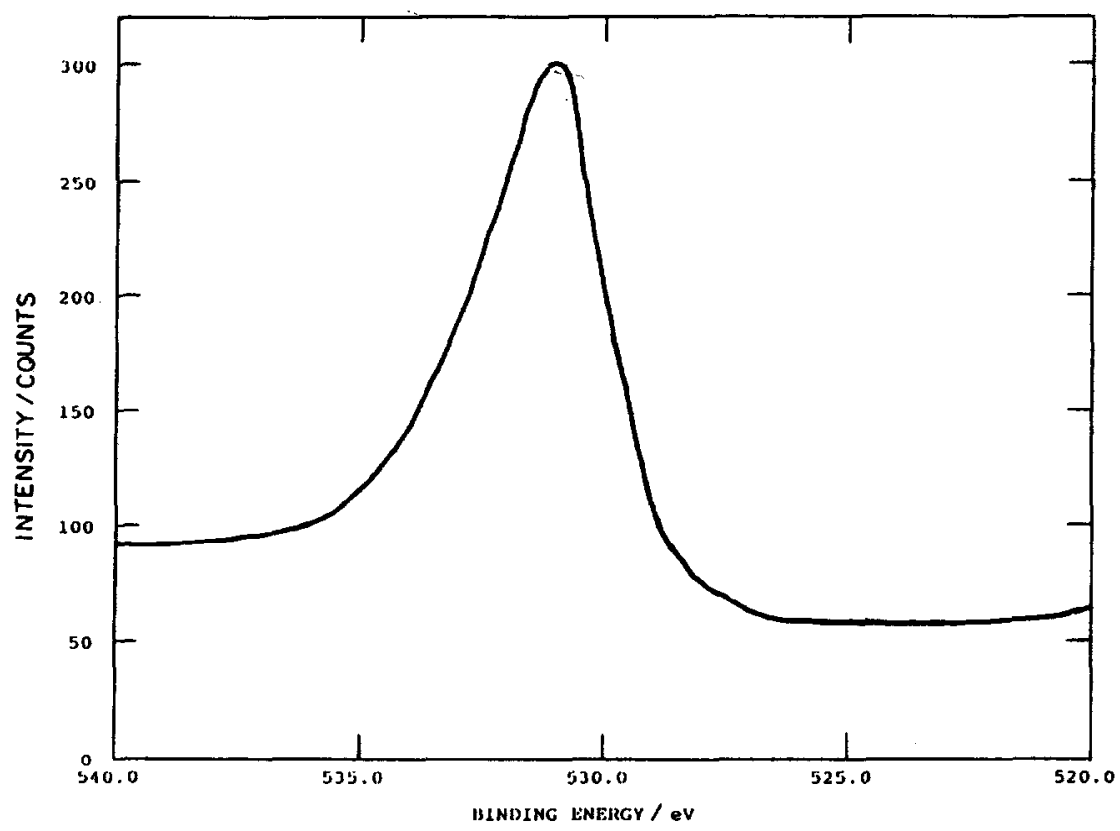

Fig. 14. $O$ 1s spectrum of both $\mathrm{FeNPc}(1.2)$ and $\mathrm{CoNPc}(1.2)$ after storage for 10 days in acid solutions. No effect of heat treatment was observed.

groups at the catalyst-carbon black interface. Therefore we used the FABS technique to investigate this phenomenon further.

\section{FABS measurements}

Depending upon the acceleration voltage applied to the source either negative or positive ions are detected. The positive mode allows the detection of protonation which may take place either in the samples or as a secondary effect in the gas phase during the experiment. In the negative mode no eventual positive protonation is detected, but any negatively charged molecules or radicals will be displayed.

FABS data (intensities versus mass number) obtained in the positive mode for non-heat-treated and heat-treated CoNPc samples after storage for 10 days in acid solution are shown in Figs. 17(a) and 17(b) respectively. Data obtained for these samples in the negative mode are shown in Figs. 17(c) and 17(d) respectively. Figure 17(e) shows negative mode data for the unsupported powder.

The similarity between Figs. 17(a) and 17(b) should be noted. Peaks at mass numbers of $613,460.1,443,307,289,153.9,136.2$ and below can be attributed to the NBA matrix, whereas those at 790.1 and 899.2 can be assigned to the samples under investigation. The compound at mass number 790.1 can be identified as a CoNPc molecule protonated and attached to a water molecule. It is not present in the data for the unsupported powder nor in Figs. 17(c) and 17(d). Higher mass 

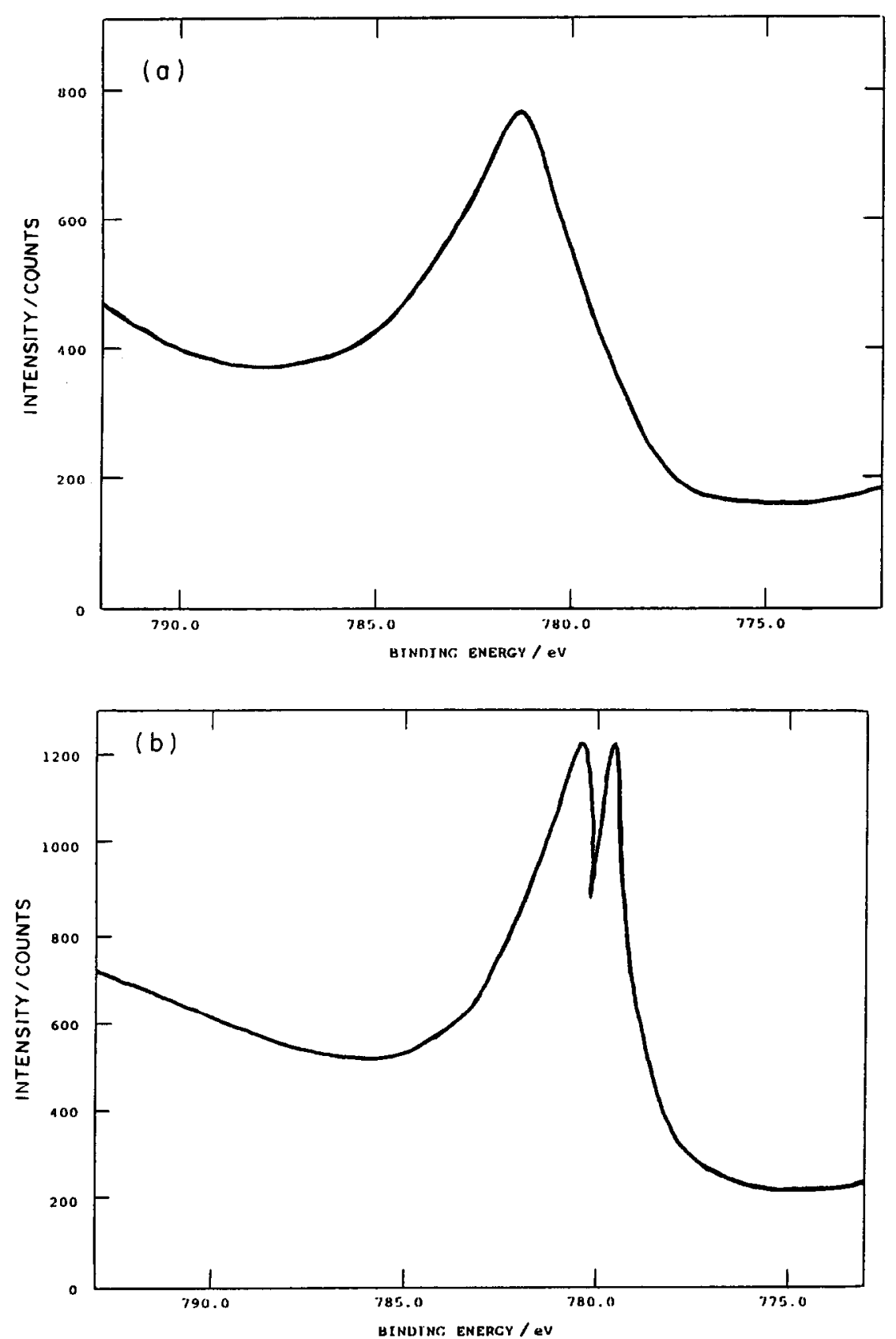

Fig. 15. Co $2 p$ spectra of (a) samples after storage for 10 days in acid solution (heat-treated and non-heat-treated) and (b) heat-treated samples not stored in acid solution. 

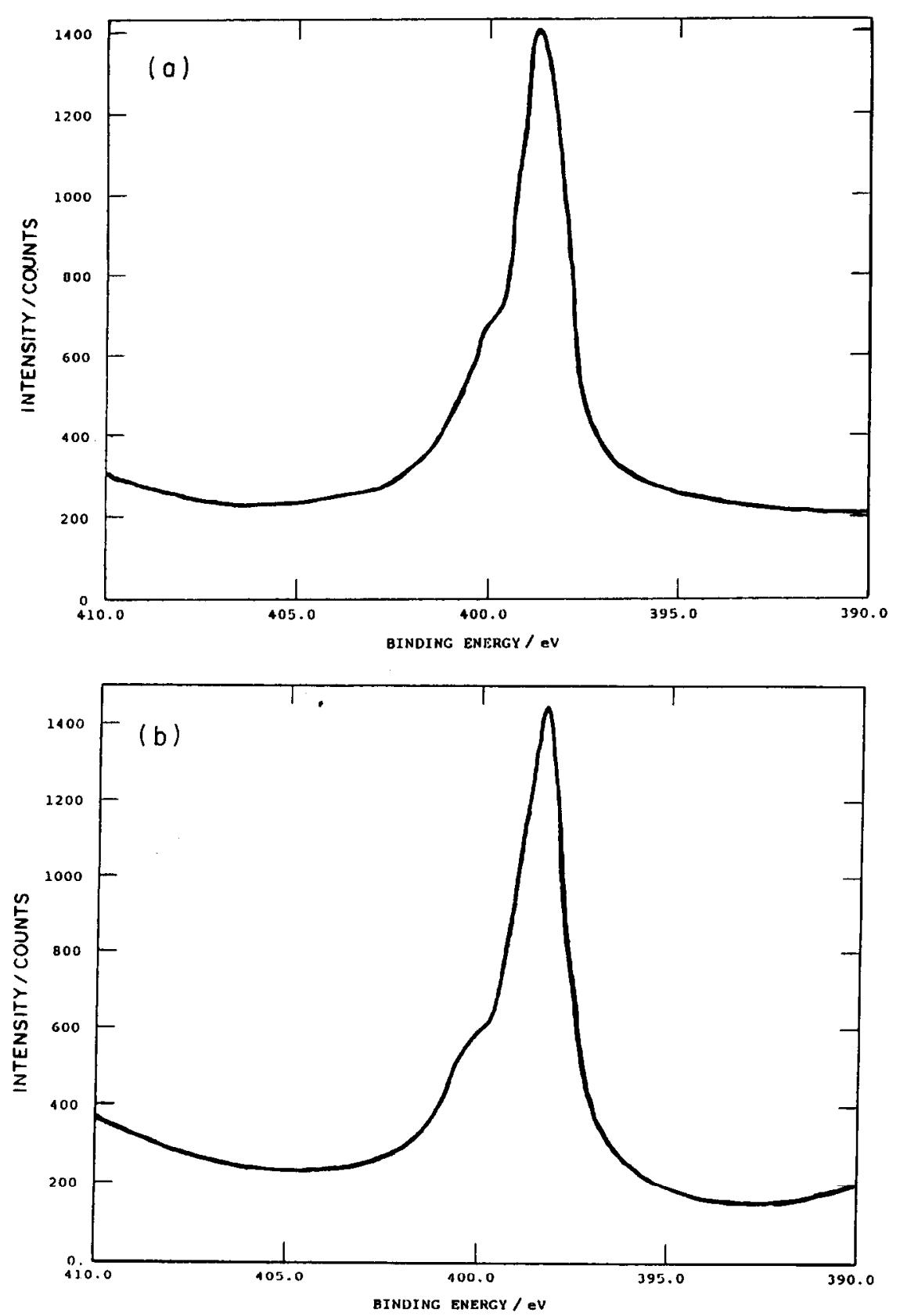

Fig. 16. N 1s spectra of NPcCo(1.2) on Printex XE2: (a) non-heat-treated samples; (b) heat-treated samples; (c) non-heat-treated samples after storage for 10 days in acid solution; (d) heat treated samples after storage for 10 days in acid solution. 

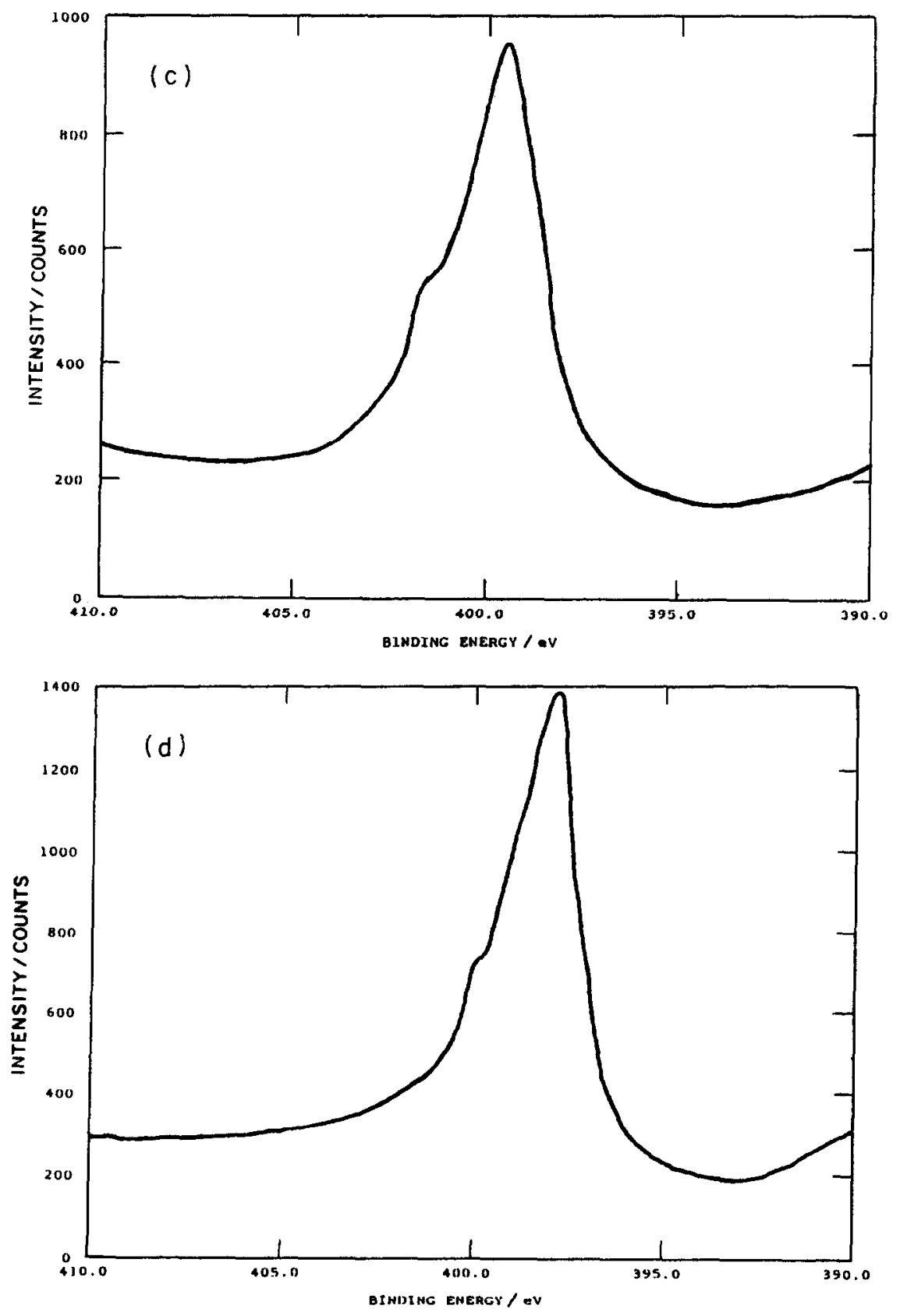

Fig. 16 (continued). 

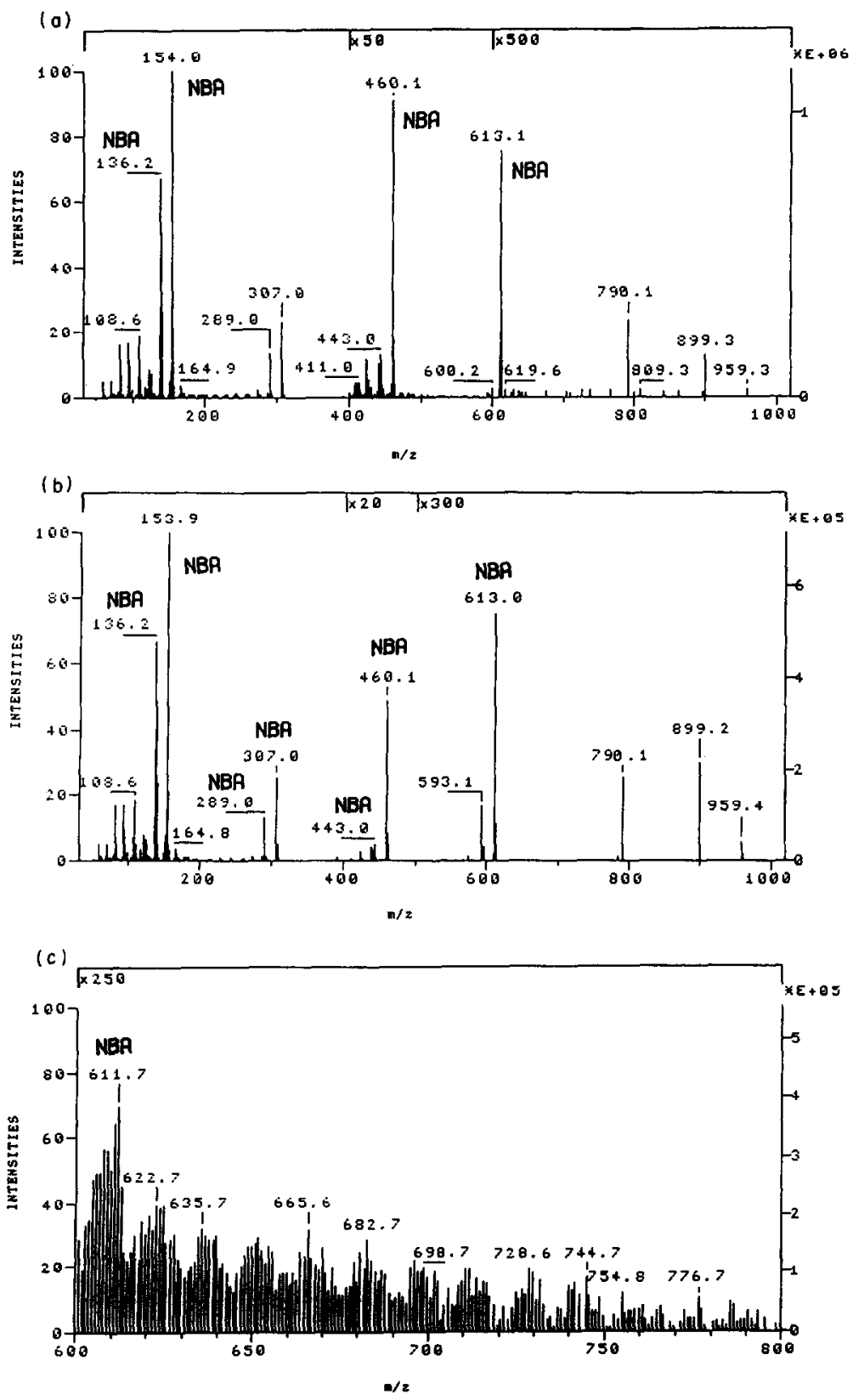

Fig. 17. FABS data (intensities versus mass number) for the CoNPc(1.2) samples loaded at $27 \%$ after storage for 10 days in acid solution: (a) non-heat-treated (positive mode); (b) heat-treated (positive mode); (c) non-heat-treated (negative mode); (d) heat-treated (negative mode); (e) unsupported CoNPc(1.2) powder (negative mode). 

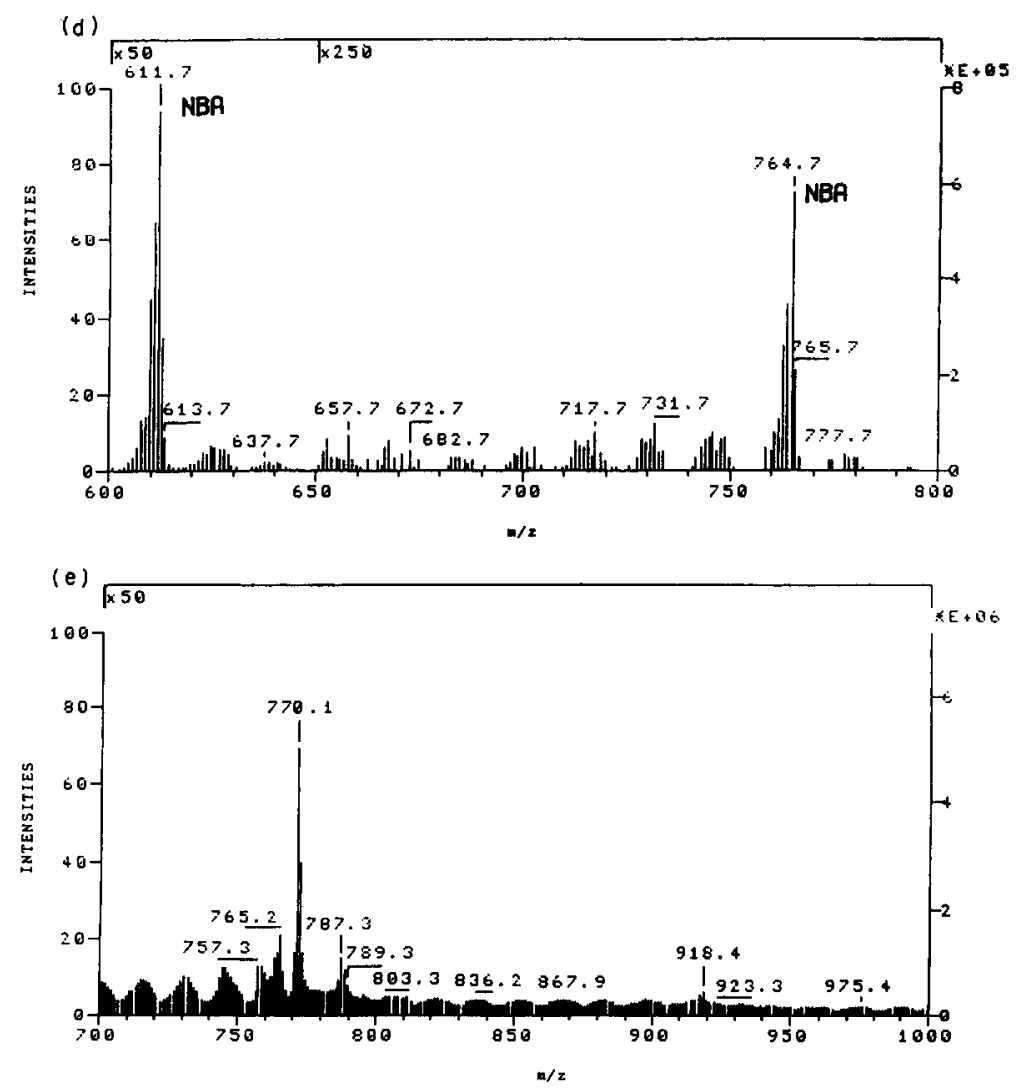

Fig. 17 (continued).

numbers, absent in the unsupported powder, also suggest a chemical bond between CoNPc molecules and the carbon black surface groups.

The major difference between Figs. 17(c) and 17(d) (negative mode data) is the larger number of peaks, forming a quasi-continuum, which are obtained for the non-heat-treated samples. These data emphasize the presence of various possible electron-trapping groups at the carbon black-catalyst interface. During the heat treatment they can act as reservoirs, yielding electrons to the accepting species which, from XPS data, are mainly the $\mathrm{O}_{2}$ molecules inserted in the catalyst layers. After their elimination, accompanied by oxygen loss, the passage of electrons from the carbon black surface to the oxygen or nitrogen sites may be enhanced. This conclusion is confirmed by the XPS data presented above.

The peak at mass number 764.7 is characteristic of NBA.

\section{CONCLUSION}

In this paper the beneficial aspects of substitution of $\mathrm{Fe}$ by $\mathrm{Co}$ in $\mathrm{NPc}(1.2)$ impregnations on an active carbon black support has been shown. Within a useful 
range of potentials, electrochemical activities comparable with those of $10 \% \mathrm{Pt}$ on Vulcan were found.

The application of XPS and FABS techniques has shed some light on the structure of the catalyst layers and on their interactions with the support, yielding some information on the effects of heat treatment. Whereas in the case of FeNPc(1.2) optimal activity is reached for monolayer coverage, improved activities can be obtained using several CoNPc layers. The main difference between $\mathrm{CoNPc}(1.2)$ and $\mathrm{FeNPc}(1.2)$ catalysts is the absence of demetallation after prolonged exposure to acid solutions for CoNPc.

In the case of FeNPc samples, heat treatment results in an improvement of the dispersion as long as monolayer coverage can take place. This process is accompanied by partial oxidation of the inner nitrogen sites. In the case of CoNPc samples, these sites appear more negatively charged after heat treatment. FAB and XPS data show that this effect can be correlated with the elimination of some electrophilic surface groups at the carbon black-catalyst interface via moderate oxidation by the inserted oxygen molecules. These results emphasize the rôle of the inner nitrogen sites in the electrochemical processes (adsorption and transfer) and stress the electron-donor effect of the carbon black surface groups.

In the case of multilayer catalysts, the substitution of $\mathrm{Fe}$ by Co is likely to result in an increase in their conductivity because of the mixture of $\mathrm{Co}$ (II) and $\mathrm{Co}(\mathrm{III})$.

\section{ACKNOWLEDGMENTS}

The authors acknowledge l'Agence Française pour la Maîtrise de l'Energie for its financial support under contract 9030042 . The authors are indebted to Ing. T.W. Stevens, Twente University, for performing the FABS experiments and for his helpful comments.

\section{REFERENCES}

1 M. Kirschenmann, D. Wohrle and W. Vielstich, Ber. Bunsenges. Phys, Chem., 92 (1988) 1403.

2 Ch. Fabjan, G. Frithum and H. Hartl, Ber. Bunsenges. Phys. Chem., 94 (1990) 937.

3 C. Fierro, A.B. Anderson and D.A. Scherson, J. Phys. Chem., 92 (1988) 6902.

4 R. Franke, D. Ohms and K. Wiesener, J. Electroanal. Chem., 260 (1989) 63.

5 D. Wohrle, D. Schlettwein and M. Kirschenmann, J. Macromol. Sci. Chem., A27 (9-11) (1990) 1239.

6 O. Ikeda, S. Itoh and H. Yoneyama, Bull. Chem. Soc. Jpn., 61 (1988) 1428.

7 A. Bettelheim, B.A. White and R.W. Murray, J. Electroanal. Chem., 217 (1987) 271.

8 V. van Wingerden, J.A.R. van Veen and C.T.J. Menseh, J. Chem. Soc. Faraday Trans., 84(1) (1988) 65.

9 J. McBreen, Proc. Electrochem. Soc., 87 (1987) 182.

10 A. Biloul, F. Coowar, O. Comamin, M. Savy, D. van den Ham, J. Riga and J.J. Verbist, J. Electroanal. Chem., 289 (1990) 189.

11 F. Coowar, O. Contamin, M. Savy, D. van den Ham, J. Riga and J.K. Verbist, J. Electroanal. Chem., $282(1990) 141$.

12 F. Coowar, O. Contamin, M. Savy, D. van den Ham, J. Riga and J.J. Verbist, J. Electroanal. Chem., 269 (1989) 143. 
13 A. Biloul, F. Coowar, O. Contamin, G. Scarbeck, M. Savy, D. van den Ham, J. Riga and J.J. Verbist, J. Electroanal. Chem., 328 (1992) 219.

14 A.M. Schaffer, M. Gouterman and E.R. Davidson, Theor. Chim. Acta, 30(9) (1973) 30.

15 A.B.P. Lever, S. Liccocia, K. Magnell, P.C. Minor and B.S. Ramasuramy, Adv. Chem. Ser., 201 (1982) 237.

16 P.C. Minor, M. Gouterman and A.B.P. Lever, Inorg. Chem., 24 (1985) 1894.

17 J. Koutecky and V.G. Levich, Dokl. Akad. Nauk USSR, 117 (1957) 441; Zh. Fiz. Khim., 32 (1958) 1565.

18 R.R. Durand and F.C. Anson, J. Electroanal. Chem., 134 (1982) 273.

19 O. Contamin and E. Levart, J. Electroanal. Chem., 136 (1982) 259.

20 D.M. Hercules and J.C. Klein, in H. Windawi, F. Floyd and F.L. Ho (Eds.), Applied Electron Spectroscopy for Chemical Analysis, Wiley, New York, 1982, p. 147.

21 H. Windawi, F. Floyd and C.D. Wagner, in H. Windawi, F. Floyd and F.L. Ho (Eds.), Applied Electron Spectroscopy for Chemical Analysis, Wiley, New York, 1982, p. 191.

22 I. Elliot, C. Doyle and J.D. Anduade, J. Electron. Spectrosc. Relat. Phenomen., 28 (1983) 303. 